\title{
Struktur Komunitas Ikan Karang dan Tutupan Karang pada Terumbu Buatan Artificial Patch Reef (APR)
}

\author{
Munasik $^{1 *}$, Aldion Adin Nugroho', Retno Hartati', Agus Sabdono', \\ Sugiyanto², Denny Nugroho Sugianto ${ }^{3}$ \\ 'Departemen IImu Kelautan, Fakultas Perikanan dan IImu Kelautan, Universitas Diponegoro \\ 2Departemen Teknik Mesin, Fakultas Teknik, Universitas Diponegoro \\ 3Departemen Oseanografi, Fakultas Perikanan dan Ilmu Kelautan, Universitas Diponegoro \\ JI. Prof. Soedarto SH Tembalang, Semarang 50275, Indonesia \\ Email: munasik@lecturer.undip.ac.id
}

\begin{abstract}
Community structure of reef fishes and coral coverage on the artificial patch reefs (APR)
\end{abstract}

Artificial Patch Reef (APR) have been applied as a new method for Biodiversity Conservation Program at Panjang Island, Jepara since 2015. Previous study suggested that design and location of artificial reefs installation affected to abundance of reef fishes, associated with the artificial reef. This study aims to investigated community structure of reef fishes associated to artificial patch reef comparing to reef fishes in nearby natural reefs. Assessment of coral reef condition on two habitats were conducted on July 2019, after 4 years deployment. The results show that artificial patch reefs with a percentage of live coral cover are less than half of natural coral reefs, and have succeeded in increasing the abundance of reef fish with nearly the same density and community structure resembling reef fish in natural coral reefs. The similarity in community structure of the two habitats is probably due to the similarity in habitat type and morphology of the hard corals. The results indicate that Artificial Patch Reef (APR) reefs have increased the coral cover of Acropora branching and resulted in increased reef fish abundance which is compatible with reef fish communities associated with natural coral reefs around it.

Keywords: reef fishes; density; artificial reefs; Panjang Island; Jepara

\begin{abstract}
Abstrak
Aplikasi metode baru terumbu buatan Artificial patch Reef (APR) pada Program Konservasi Bioiversitas Pulau Panjang, Jepara telah dilakukan sejak 2015. Hasil studi menunjukkan bahwa pemilihan desain dan lokasi pemasangan terumbu buatan yang tepat akan meningkatkan kelimpahan ikan karang. Tujuan penelitian ini adalah untuk mengetahui keberhasilan penerapan terumbu buatan APR melalui kelimpahan ikan karang yang berasosiasi pada terumbu buatan dan terumbu karang alami di sekitarnya. Penilaian kondisi terumbu karang tersebut telah dilakukan pada Juli 2019 setelah 4 (empat) tahun pemasangan terumbu buatan. Hasil studi menunjukkan bahwa terumbu buatan dengan persentase tutupan karang hidup lebih kecil, separuhnya dari tutupan pada terumbu karang alami telah berhasil meningkatkan kelimpahan ikan karang dengan densitas hampir sama dan struktur komunitasnya menyerupai ikan karang yang berasosiasi dengan terumbu karang alami. Kesamaan struktur komunitas kedua habitat kemungkinan akibat kesamaan tipe habitat dan morfologi karang keras penyusunya. Hasil ini mengindikasikan bahwa terumbu buatan Artificial patch Reef (APR) telah meningkatkan tutupan karang bercabang Acropora dan berakibat terhadap meningkatnya kelimpahan ikan karang yang sesuai dengan komunitas ikan karang yang berasosiasi dengan terumbu karang alami di sekitarnya.
\end{abstract}

Kata kunci: ikan karang; densitas; terumbu buatan; Pulau Panjang; Jepara 


\section{PENDAHULUAN}

Terumbu buatan (artificial reefs) adalah struktur yang ditenggelamkan di dasar perairan laut yang bertujuan seperti habitat terumbu karang, yang berperan sebagai tempat perlindungan, tempat regenerasi, pengumpul serta dapat meningkatkan populasi sumberdaya biota laut (UNEP, 2009). Terumbu buatan secara tradisional telah lama diterapkan oleh para nelayan di Indonesia sebagai upaya penguumpulan ikan yang bertujuan untuk meningkatkan hasil tangjapan ikan. Struktur buatan umumnya dibuat dengan menggunakan bahan-bahan alami, seperti bambu, kayu dan. Kemudian pada penerapan berikutnya, periode tahun 90-an terumbu buatan telah diaplikasikan untuk rehabilitasi dan restorasi terumbu karang yang umumnya dengan menenggelamkan substrat beton. Beberapa kombinasi beton ban bekas yang di rangkai digunakan untuk tujuan pengumpulan ikan. Kemudian pada perkembangan berikutnya, berbagai desain substrat terumbu buatan telah digunakan, seperti bentuk kubus, reef ball, pyramid, pipa, dan lain-lain (Munasik, 2009). Setelah dikenalnya teknologi transplantasi karang (Abelson, 2006), teknologi kombinasi substrat beton dan transplantasi karang telah diterapkan pada program rehabilitasi terumbu karang di beberapa perairan Indonesia. Namun, karena kurangnya studi yang mendasari dalam pengembangan terumbu buatan di Indonesia, sehingga program rehabilitasi terumbu karang kurang optimal.

Program perlindungan ekosistem terumbu karang Pulau Panjang, Kabupaten Jepara telah dilakukan sejak 2015 dengan menerapkan teknologi terumbu buatan Artificial Patch Reef (APR) yang bertujuan untuk restorasi habitat perairan dangkal (Munasik et al., 2018). Kombinasi aplikasi substrat beton modular yang dipasang bersusun dan membentuk struktur melingkar di dasar perairan dengan penerapan transplantasi karang pada substrat struktur bertingkat. Hasil monitoring awal pada beberapa unit terbatas menunjukkan terdapatnya ikan karang yang berasosiasi dengan terumbu buatan APR. Ikan karang yang berasosiasi dengan terumbu buatan merupakan salah satu indikator keserhasilan aplikasi terumbu buatan (Paxton et al., 2020a). Hasil studi di perairan laut Jawa, bahwa desain dan bentuk terumbu buatan dipercaya telah mempengaruhi kelimpahan ikan karang (Yanuar dan Aunurrohim, 2015), tetapi studi Komyakova et al. (2019) di perairan subtropik merekomendasikan bahwa tidak hanya desain dan tipe terumbu buatan saja tetapi lokasi penyebaran terumbu buatan lebih dominan dalam mempengaruhi struktur komunitas ikan karang. Terumbu buatan Artificial Patch Reef (APR) dengan desain vertikal telah dipasang disekitar terumbu karang alami di Pulau Panjang, untuk mengetahui keberhasilan struktur tersebut telah dilakukan studi kelimpahan ikan karang yang berasosiasi pada terumbu buatan dan terumbu karang alami. Tujuan penelitian ini adalah untuk mengetahui tutupan karang hidup dan struktur komunitas ikan karang pada Artificial Patch Reef (APR).

\section{MATERI DAN METODE}

Penelitian dilakukan melalui penilaian kondisi terumbu karang, persentase tutupan karang hidup, kelimpahan dan keragaman jenis ikan karang pada terumbu karang alami dan terumbu buatan Artificial patch Reef (APR) di Pulau Panjang, Kabupaten Jepara

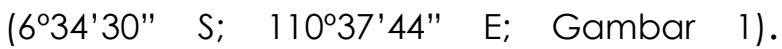
Penilaian kondisi terumbu buatan dan kelimpahan ikan karang dilakukan pada Juli 2019, merupakan bagian dari program monitoring terumbu buatan APR. Habitat terumbu buatan terbentuk, hasil dari Program perlindungan biodiversitas Pulau Panjang telah memasang 2 unit Artificial Patch Reef (APR) pada tahun 2015, kemudian berturutturut sebanyak 9 unit APR pada 2016 dan 1 unit APR pada tahun 2017 sehingga total unit terumbu buatan sebanyak 12 unit terletak memanjang tegak lurus pantai di sisi timur laut Pulau Panjang. Dua belas unit terumbu buatan tersebut telah ditumbuhi karang transplant Acropora bercabang dan saat ini telah berkembang menjadi kelompok patch reef baru dengan tutupan karang transplant sebanyak 1625 koloni.

Kondisi terumbu karang terumbu buatan diamati dengan meletakkan meteran 
pita (roll meter) di atas kelompok terumbu buatan sepanjang $100 \mathrm{~m}$ dan pengambilan data dilakukan metode Point Intercept Transect (PIT; Hill \& Wilkinson, 2004). Sedangkan kondisi terumbu karang alami berjarak sekitar $300 \mathrm{~m}$ juga dilakukan dengan memasang meteran pita sepanjang $100 \mathrm{~m}$ sejajar dengan garis pantai atau secara horizontal pada hamparan terumbu karang. Selanjutnya, kelimpahan ikan karang diamati melalui sensus visual (visual census) pada area transek sabuk (belt transect) dengan menggunakan garis imajiner $1 \mathrm{~m}$ kiri-kanan berpatokan dari meteran pita (yang telah digunakan pada pengamatan kondisi terumbu karang; English et. al., 1997). Hasil sensus visual kelimpahan ikan karang per satuan luas transek $\left(200 \mathrm{~m}^{2}\right)$ selanjutnya diperoleh data densitas ikan karang yang berasosiasi dengan terumbu buatan dan terumbu karang alami. Untuk menggambarkan sebaran ikan karang yang berasosiasi dengan setiap terumbu buatan APR, kelimpahan ikan karang juga dihitung di setiap unit APR. Keragaman jenis ikan karang dihitung dengan menggunakan indeks ' ${ }^{\prime}$ (Diversity Index). Kondisi terumbu karang dinyatakan berdasarkan persentase tutupan karang hidup dengan mengelompokkan berdasarkan bentuk pertumbuhan (life form) karang keras dan biota benthic lainnya (English et. al., 1997). Identifikasi jenis ikan karang dilakukan berdasarkan ciri-ciri morfologi merujuk pada Allen (2000) dan Allen \& Adrim (2003). Selanjutnya mengetahui perbandingan kelimpahan ikan karang yang berasosiasi dengan terumbu buatan APR dan terumbu karang alami, data densitas ikan karang yang diperoleh kemudian dianalisis dengan uji Wilcoxon Signed Rank Test menggunakan piranti lunak SPSS Statistics 22.

\section{HASIL DAN PEMBAHASAN}

Kondisi terumbu karang antara terumbu buatan APR dan terumbu karang alami menunjukkan perbedaan, yaitu tutupan karang hidup pada terumbu karang alami menjukkan dua kali lebih tinggi daripada di terumbu buatan APR (Tabel 1). Persentase tutupan karang hidup pada APR sebesar 22,5 $\%$ sedangkan tutupan karang hidup di terumbu karang alami sebesar $52 \%$. Terumbu buatan APR didominasi oleh karang Acropora dengan sedikit tutupan kelompok karang Non-Acropora, sedangkan substrat

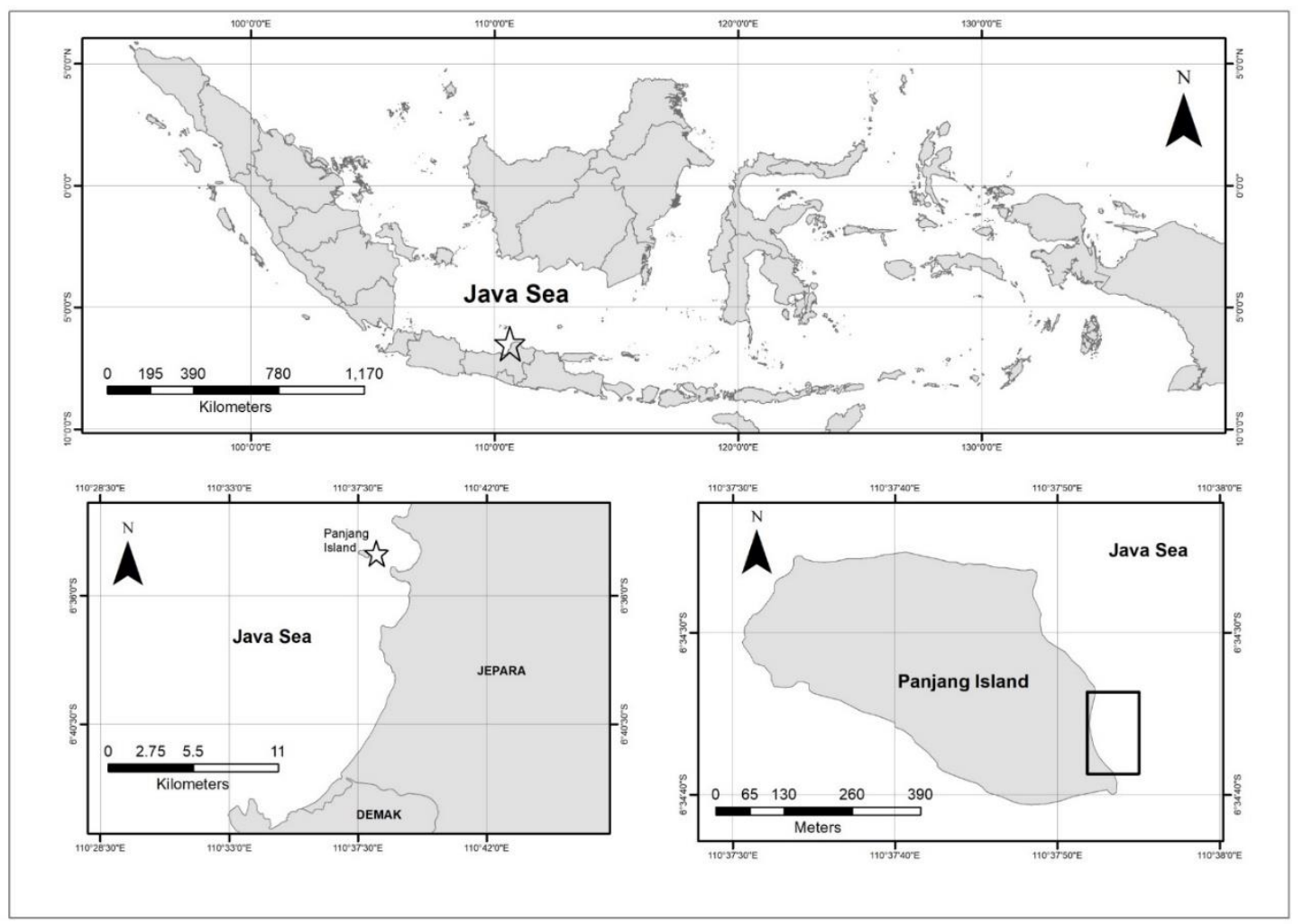

Gambar 1. Peta lokasi penelitian di Pulau Panjang, Kabupaten Jepara, Jawa Tengah 
penyusun terumbu karang alami karang Acropora hampir sama dengan tutupan karang Non-Acropora. Substrat abiotik penyusun terumbu buatan APR didominasi oleh komunitas lamun (seagrass) sedangkan pada terumbu karang alami didominasi pecahan karang (rubble). Secara umum kondisi terumbu karang Pulau Panjang Kab. Jepara dalam kategori sedang (Indarjo et al., 2004; Suryono et al., 2017) akan tetapi sebaran terumbu karang tidak merata di seluruh garis pantai pulau bahkan ancaman sedimentasi berpotensi mengurangi tutupan terumbu karang (Munasik et al., 2012). Upaya restorasi terumbu karang melalui pemasangan terumbu buatan APR dengan cara perbanyakan koloni Acropora bercabang (Munasik et al. (2018) telah berkontribusi menambah tutupan karang hidup sebesar 22,5\%. Perbaikan teknologi restorasi terumbu karang melalui aplikasi APR ini telah meningkatkan kelulushidupan dan pertumbuhan karang Acropora secara siginifikan (Munasik et al., 2020). Aplikasi pemasangan terumbu buatan APR di Pulau Panjang telah meningkatkan tutupan karang, hal ini diduga oleh keberadaan penyusun substrat dasar berupa komunitas lamun dan pasir yang berperan mengurangi resuspensi sedimen di dasar perairan.

Densitas ikan karang antara terumbu buatan APR dan terumbu karang alami tidak berbeda nyata $(P>0,05)$, yaitu 3,44 individu $/ \mathrm{m}^{2}$ di terumbu buatan APR sedangkan pada terumbu karang alami sebesar 4,76 individu/m² (Tabel 2). Hal ini menunjukkan bahwa kelimpahan ikan karang yang berasosiasi dengan terumbu buatan APR hampir sama dengan kelimpahan ikan karang di terumbu karang alami. Hal ini kemungkinan terkait lokasi terumbu buatan yang berdekatan dengan terumbu karang alami, serta lama waktu pemasangan terumbu buatan (Chase \& Hoogenboom, 2019). Struktur komunitas ikan karang pada terumbu buatan akan lebih menyatu dengan terumbu karang alami seiring dengan waktu (Komyakova et al., 2019). Awal pengamatan kelimpahan dan keragaman jenis ikan karang pada terumbu buatan APR sangat rendah, 15-20 individu dari 5 jenis ikan karang (Munasik et al., 2018) setelah empat tahun pemasangan, kelimpahan dan komposisi jenis ikan karang pada terumbu buatan APR telah meningkat signifikan. Pemasangan terumbu buatan dan transplantasi karang di beberapa perairan di Indonesia dapat meningkatkan kelimpahan dan komposisi jenis ikan karang (Fadli et al., 2012; Manembu et al., 2014). Peningkatan populasi ikan pada habitat Terumbu buatan APR di perairann dangkal Pulau Panjang ini kemungkinan akibat kontribusi komunitas lamun di sekitar terumbu buatan sebagai daerah asuhan ikan karang sehingga hal ini sangat mendukung peningkatan kelimpahan ikan di terumbu buatan. Susilo et al. (2018) membuktikan bahwa tutupan lamun mempengaruhi kelimpahan ikan.

Kelimpahan ikan tertinggi berdasarkan family pada kedua habitat ditemukan pada kelompok Pomacentridae, kemudian berturut-turut kelompok Chaetodontidae, Apogonidae dan Labridae. Kelimpahan ikan karang tergolong tinggi umumnya dari kelompok ikan mayor dan ikan indikator (Gambar 2). Ikan karang Pomacentridae dan Apogonidae umumnya ditemukan dominan

Tabel 1. Persentase tutupan karang hidup (\%) pada terumbu buatan APR dan terumbu karang alami di Pulau Panjang, Jepara Tahun 2019

\begin{tabular}{cccccc}
\hline \multirow{2}{*}{ Kategori Biota } & \multicolumn{2}{c}{ APR } & \multicolumn{2}{c}{ Terumbu Karang Alami } \\
\cline { 2 - 5 } & Jumlah Titik & Persentase & Jumlah Titik & Persentase \\
\hline Acropora & 41 & 20.5 & 50 & 25 \\
Non-Acropora & 4 & 2 & 54 & 27 \\
Fleshy Seaweed & 16 & 8 & 16 & 8 \\
Rubble & 17 & 8.5 & 39 & 19.5 \\
Rock & 11 & 5.5 & 15 & 7.5 \\
Sand & 25 & 12.5 & 12 & 6 \\
Seagrass & 86 & 43 & 14 & 52 \\
\hline Persentase Tutupan Karang Hidup & & 22.5 & & & 5 \\
\hline
\end{tabular}


Tabel 2. Kelimpahan Ikan Karang (ind $/ \mathrm{m}^{2}$ ) pada terumbu buatan APR dan terumbu karang alami di Pulau Panjang, Jepara Tahun 2019

\begin{tabular}{llcc}
\hline Famili & \multicolumn{1}{c}{ Jenis Ikan } & Terumbu Buatan & Terumbu Alami \\
\hline & Chromis xanthura & 1,24 & 1,10 \\
& Neopomacentrus cyanomos & 0,38 & 0,42 \\
& Pomacentrus brachialis & 0,40 & 0,38 \\
Pomacentridae & Dascylus reticulus & 0,01 & 0,07 \\
& Pomacentrus auriventris & 0,01 & 0,07 \\
& Pomacentrus xanthostemus & 0,01 & 0,09 \\
& Chromis elerae & - & 0,43 \\
Scaridae & Abudefduf sexfasciatus & - & 0,22 \\
Serranidae & Scarus ghobban & 0,01 & 0,05 \\
Siganidae & Plectropomus macullatus & 0,01 & 0,01 \\
Apogonidae & Cephalopholis boenak & 0,01 & 0,01 \\
Chaetodontidae & Siganus virgatus & - & 0,16 \\
Labridae & Apogon endekataenia & 0,32 & 0,26 \\
& Chaetodon octofasciatus & 0,87 & 0,98 \\
Lutjanidae & Halichoeres hortulamus & 0,09 & 0,15 \\
Mullidae & Halichoeres richmondi & 0,05 & 0,14 \\
& Lutjanus ehrenbergii & 0,01 & 0,02 \\
& Lutjanus decussatus & 0,02 & 0,02 \\
& Parupeneus indiscus & - & 0,18 \\
\hline
\end{tabular}

pada terumbu buatan di perairan dalam (Manembu et al., 2014; Faizah et al., 2020). Sedangkan family ikan karang yang dapat ditemukan di kedua habitat baik pada habitat buatan maupun alami dengan kelimpahan rendah, yaitu kelompok ikan target Seranidae dan Lutjanidae. Kelompok ikan yang ditemukan di habitat alami namun tidak dijumpai pada habitat buatan adalah family Siganidae dan Mullidae (Gambar 3). Jenis ikan karang Pomacentridae yang banyak ditemukan di terumbu buatan dengan posentase kemunculan lebih dari 50\% adalah Chromis xanthura (83\%), Neopomacentrus cyanomos (75\%), sedangkan jenis lainnya adalah Chaetodon octofasciatus (83\%) dari Family Chaetodontidae. Asosiasi ikan karang Chromis xanthura ditemukan berkelompok hingga 30 individu per unit APR sedangkan Chaetodon octofasciatus umumnya ditemukan berpasangan dan dapat mencapai 16 individu per unit APR. Jenis ikan Apogonidae yang ditemukan di terumbu buatan APR tidak merata hanya Apogon endekataenia yang ditemukan berkelompok hingga 35 individu per unit APR. Chromis xanthura adalah ikan karang Pomacentrid yang umum ditemukan berasosiasi dan menetap pada terumbu karang (reef associate, non-migratory) sedangkan Chaetodon octofasciatus ikan indikator kesehatan terumbu karang ini berasosiasi dengan terumbu karang, utamanya pada koloni Acropora. Tutupan karang Acropora pada terumbu buatan APR maupun terumbu karang alami memiliki prosentase yang tinggi, diduga mempengaruhi komunitas ikan karang yang bersasosiasi. Hasil studi menunjukkan bahwa perbedaan bentuk koloni (lifeform) karang keras berpengaruh terhadap jenis-jenis ikan karang yang berasosiasi, koloni karang bercabang Acropora memiliki asosiasi terhadap ikan karang Pomacentridae (Bonin, 2012) maupun Chaetodontidae (Madduppa et al., 2014).

Keragaman jenis ikan karang di kedua habitat menunjukkan kategori sedang, dengan Indeks Keragaman jenis ( $\left.\mathrm{H}^{\prime}\right)$ ikan di terumbu buatan sebesar 1,7 dan Indeks $\mathrm{H}^{\prime}$ terumbu karang alami sebesar 2,37. Kesamaan struktur komunitas ikan karang pada terumbu buatan APR dengan terumbu alami kemungkinan dipengaruhi oleh dimensi dan bentuk terumbu buatan APR yang menyerupai terumbu alami di Pulau Panjang. Komunitas Pomacentridae yang berasosiasi dengan terumbu karang ditentukan oleh tipe terumbu (patch reef atau rataan terumbu) 


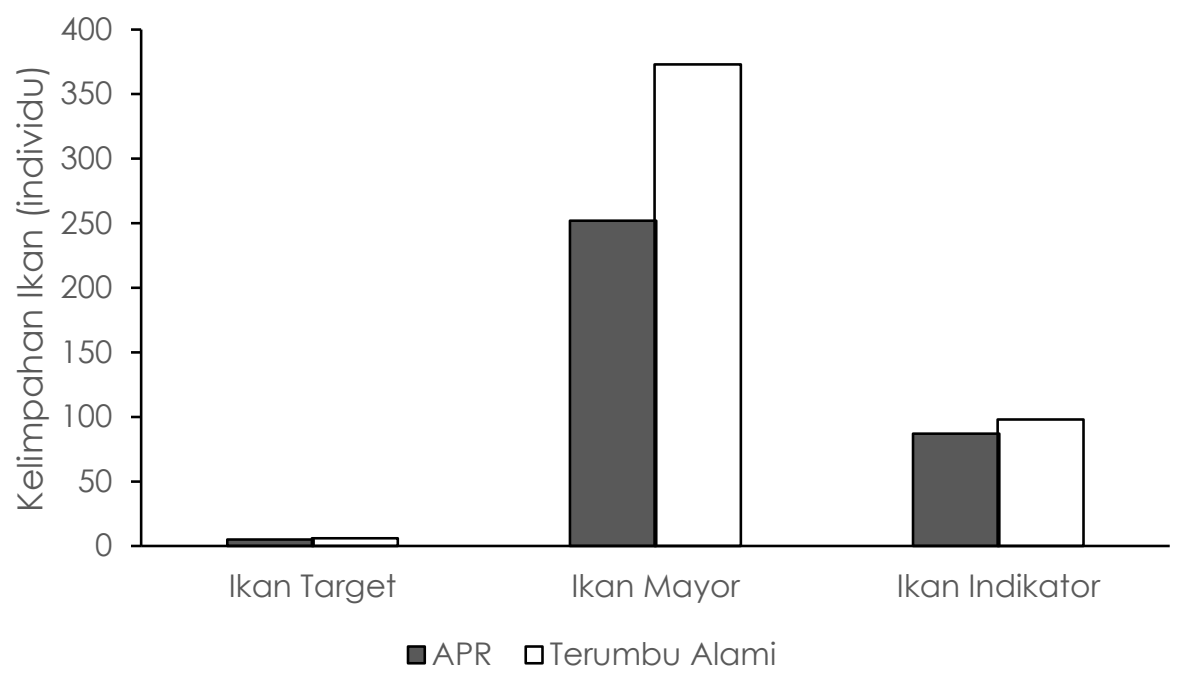

Gambar 2. Kelimpahan Ikan karang (individu) berdasarkan kelompok fungsi di Pulau Panjang, Kabupaten Jepara, Jawa Tengah

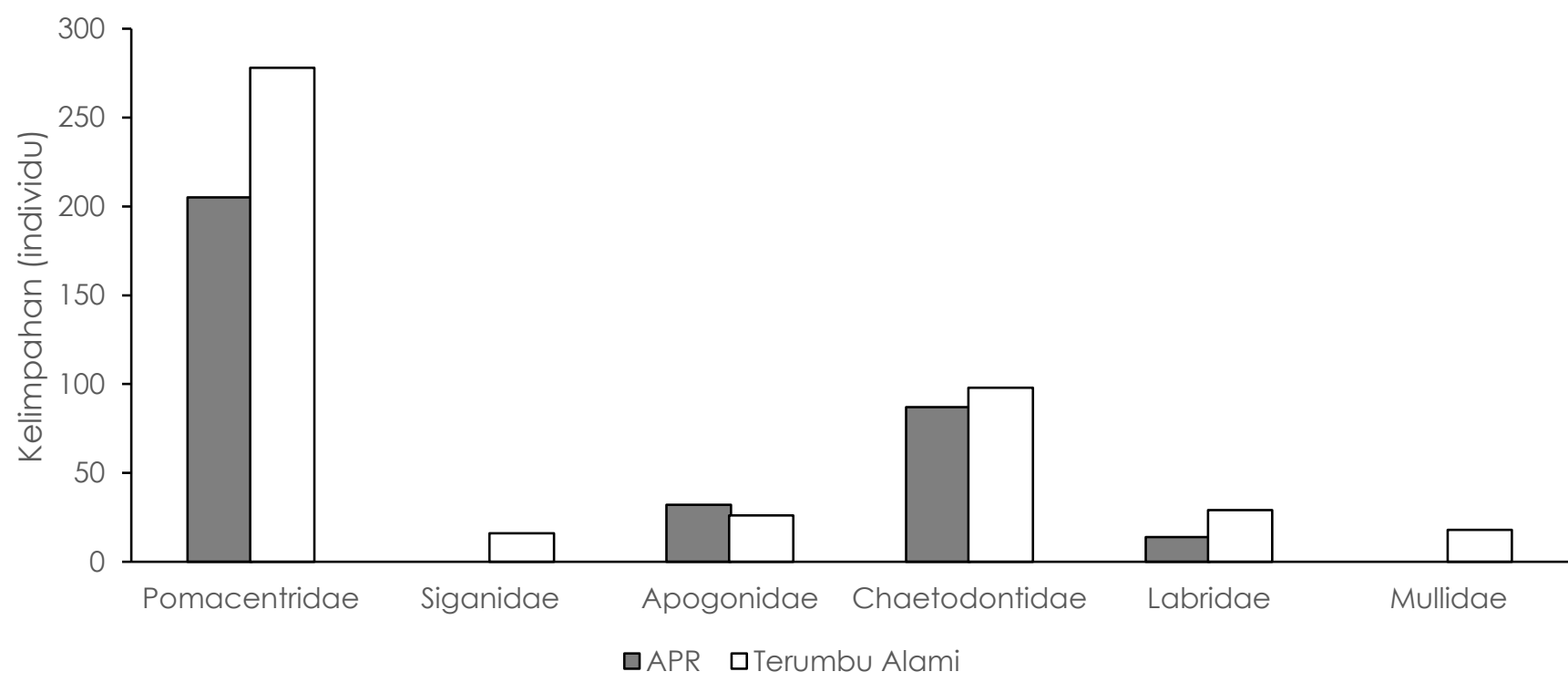

Gambar 3. Kelimpahan Ikan karang (individu) berdasarkan family di Pulau Panjang, Kabupaten Jepara, Jawa Tengah

dan komposisi bentuk pertumbuhan karang atau morfologi karang keras penyusunnya (Chase \& Hoogenboom, 2019). Struktur komunitas ikan karang yang berasosiasi dengan terumbu buatan sangat ditentukan oleh desain, bentuk dan lokasi terumbu buatan (Paxton, et al., 2020a, 2020b; Mujianto \& Sugiyanti, 2008). Dengan demikian, desain terumbu buatan patch (APR) yang ditransplantasi karang bercabang Acropora, sesuai untuk restorasi terumbu karang dalam rangka membentuk habitat baru terumbu karang di Pulau Panjang, Jepara.

\section{KESIMPULAN}

Aplikasi terumbu buatan Artificial Patch Reef (APR) telah meningkatkan tutupan karang bercabang Acropora dan berakibat meningkatnya kelimpahan ikan karang yang berasosiasi. Struktur komunitas ikan karang yang berasosiasi dengan terumbu buatan APR di Pulau Panjang, Jepara sesuai dengan setruktur komunitas ikan karang pada terumbu karang alami di sekitarnya. Komposisi jenis ikan karang didominasi oleh kelompok ikan mayor Chromis xanthura 
(Pomacentridae) dan kelompok ikan indikator Chaetodon octofasciatus (Chaetodontidae).

\section{UCAPAN TERIMAKASIH}

Artikel ini adalah bagian dari program penelitian yang didanai melalui Hibah Penelitian STRANAS 2018 (No. 101170/UN7.P4.3/PP/2018) Kementerian Riset, Teknologi dan Pendidikan Tinggi pada M, AS, $S$ and DNS serta Hibah Penelitian Terapan 2019 (No. 101-170/UN7.P4.3/PP/2019) Kementerian Riset, Teknologi dan Pendidikan Tinggi pada AS, $S$ and DNS. Terimakasih kepada PT. PLN Unit Pembangkitan Tanjung Jati $B$ atas bantuan pemasangan, monitoring dan pemeliharaan terumbu buatan Artificial Patch Reef (APR) pada Program Konservasi Biodiversitas Pulau Panjang, Kabupaten Jepara.

\section{DAFTAR PUSTAKA}

Abelson, A., 2006. Artificial reefs vs coral transplantation as restoration tools for mitigating coral reef deterioration: benefits, concerns, and proposed guidelines. Bull. Mar. Sci., 78(1):151-159.

Allen, G.R., 2000. A Field Guide for Angler and Diver: Marine Fishes of South East Asia. Periplus Edition. Singapore. 292pp.

Allen, G.R. \& Adrim, M., 2003. Coral Reef Fishes of Indonesia. Zool. Stud. 42(1):1-72.

Fadli, N., Aidia, N., Muhammad, M., \& Rudi, E., 2012. Komposisi ikan karang di lokasi transplantasi karang di Pulau Rubiah, Kota Sabang, Aceh. Depik, 1 (3):196-199

Bonin, M.C., 2012. Specializing on vulnerable habitat: Acropora selectivity among damselfish recruits and the risk of bleaching-induced habitat loss. Coral Reefs, 31:287-297. doi : 10.1007/s00338$011-0843-2$

Chase, T.J. \& Hoogenboom, M.O., 2019. Differential Occupation of Available Coral Hosts by Coral-Dwelling Damselfish (Pomacentridae) on Australia's Great Barrier Reef. Diversity, 11(11):p219. doi: 10.3390/d11110219

English, S., Wilkinson, C., \& Baker, V., 1997. Survey Manual for tropical Marine Resources. ASEAN-Australia Marine Science Project: Living Coastal
Resources, Australian Institut of Marine Science

Faizah, R., Sadiyah, L. \& Aisyah., 2020. Struktur Komunitas dan Preferensi Habitat Ikan Karang pada Terumbu Buatan di Teluk Awang dan Teluk Bumbang, Pulau Lombok. Oseano. Limnol. Indo., 5(1):61-73

Hill, J. \& Wilkinson, C., 2004. Methods for Ecological Monitoring of Coral Reefs: A Resource for Managers. Australian Institute of Marine Science and Reef Check, Australia.

Indarjo, A., Widjatmoko, W. \& Munasik., 2004. Kondisi Terumbu Karang di Perairan Pulau Panjang, Jepara. Ilmu Kelautan, 9(4): 217-224.

Komyakova, V., Chamberlain, D., Jones, G.P., \& Swearer, S.E., 2019. Assessing the performance of artificial reefs as substitute habitat for temperate reef fishes: Implications for reef design and placement. Sci. Total Environ., 668:139152, doi: 10.1016/j.scitotenv.2019.02.357)

Madduppa, H.H., Zamani, N.P., Subhan, B., Aktani, U. \& Ferse, S.C.A., 2014. Feeding behavior and diet of the eight-banded butterflyfish Chaetodon octofasciatus in the Thousand Islands, Indonesia. Environ. Biol. Fish. 97:1353-1365. doi : 10.1007/s106 41-014-0225-z

Manembu, I., Adrianto, L., Bengen, D., \& Yulianda, F., 2014. Kelimpahan Ikan Karang pada Kawasan Terumbu Buatan di Perairan Ratatotok, Sulawesi Utara. Bawal, 6(1):55-61

Mujiyanto, Y. \& Sugianti., 2008. Pengamatan komunitas ikan karang sebagai indikator keberhasilan pemasangan modul terumbu buatan di perairan Teluk Saleh, Nusa Tenggara Barat. Forum Nasional Pemacuan Sumberdaya Ikan I. Pusat Riset Perikanan Tangkap, Badan Riset Kelautan dan Perikanan. Departemen Kelautan dan Perikanan. 229-240 pp.

Munasik., 2008. Kondisi Terumbu Buatan Berbahan Beton pada Beberapa Perairan di Indonesia. In: Simposium Munas Terumbu Karang II, 20 November 2008. Hotel Bidakara Jakarta.

Munasik, Sugiyanto, Sugianto, D.N., \& Sabdono, A., 2018. Reef Development on Artificial Patch Reefs in Shallow Water Panjang Island, Central Java. IOP Conf. Series: Earth Environ. Sci. 116:012095. 
Munasik, Sabdono, A., Assyfa A.N., Wjayanti, D.P., Sugiyanto, Irwani \& Pribadi, R., 2020 Coral transplantation on a multilevel substrate of Artificial Patch Reefs: effect of fixing methods on the growth rate of two Acropora species. Biodiversitas 21 (5): 1816-1822

Paxton, A.B., Shertzer, K.W., Bacheler, N.M. Kellison, G.T., Riley, K.L. \& Taylor. J.C. 2020. Meta-Analysis Reveals Artificial Reefs Can Be Effective Tools for Fish Community Enhancement but Are Not One-Size-Fits-All. Front. Mar. Sci. 7:282. doi: 10.3389/fmars.2020.00282

Paxton, A.B., Newton, E.A., Adler, A.M., Van Hoeck, R.V., Iversen, E.S., Taylor, Jr. JC., 2020. Artificial habitats host elevated densities of large reef-associated predators. PLOS ONE, 15(9):e0237374. doi: 10.1371/journal.pone.0237374)
Suryono, Munasik, Ario, R. \& Handoyo, G., 2017. Inventarisasi Bio-Ekologi Terumbu Karang di Pulau Panjang, Kabupaten Jepara, Jawa Tengah. J. Kel. Trop. 20(1): 60-64.

Susilo, E.S., Sugianto, D.N., Munasik, Nirwani, \& Suryono, C.A., 2018. Segrass Parameter Affect the Fish Assemblages in Karimunjawa Archipelago. IOP Conf. Series: Earth Environ. Sci. 116:012058.

United Nations Environment Program (2009). London Convention and Protocol/UNEP Guidelines for the Placement of Artificial Reefs. London: United Nations Environment Programme (UNEP).

Yanuar, A. \& Aunurrohim, 2015. Komunitas Ikan Karang pada Tiga Model Terumbu Buatan (Artificial Reef) di Perairan Pasir Putih Situbondo, Jawa Timur. J. Sains dan Seni ITS, 4(1):2337-3520 